\title{
Atrial fibrillation reduction by renal sympathetic denervation: 12 months' results of the AFFORD study
}

\author{
Lida Feyz ${ }^{1}$. Dominic A. Theuns ${ }^{1} \cdot$ Rohit Bhagwandien ${ }^{1} \cdot$ Mihai Strachinaru $^{1} \cdot$ Isabella Kardys ${ }^{1}$. \\ Nicolas M. Van Mieghem ${ }^{1} \cdot$ Joost Daemen ${ }^{1}$
}

Received: 22 June 2018 / Accepted: 5 November 2018 / Published online: 10 November 2018

(c) The Author(s) 2018

\begin{abstract}
Aim The purpose of this pilot study was to assess whether renal sympathetic denervation (RDN) decreases atrial fibrillation (AF) burden in hypertensive patients with symptomatic AF at 6- and 12-month follow-up, as measured using an implantable cardiac monitor (ICM).

Methods and results A total of 20 patients with symptomatic paroxysmal or persistent AF (EHRA $\geq$ II) and primary hypertension with a mean office systolic blood pressure (BP) of $>140 \mathrm{mmHg}$ were enrolled. After enrolment, an ICM was implanted 3 months pre-RDN to monitor AF burden. Quality of life (QOL) was assessed using the Atrial Fibrillation Effect on QualiTyof-life (AFEQT) questionnaire. Mean age was $64 \pm 7$ years and $55 \%$ were females. AF burden in min/day decreased from a median (IQR) of $1.39(0-11)$ pre-RDN to $0.67(0-31.6)$ at 6 months $(p=0.64)$ and to $0.94(0-6.0)$ at 12 months (pre-RDN vs. 12 months; $p=0.03)$. QOL improved significantly at both 6 months $(+11 \pm 15$ points, $p=0.006)$ and 12 months $(+10 \pm 19$, $p=0.04)$ as compared to pre-RDN. Office BP decreased significantly at 12 -month follow-up $(-20 \pm 19 /-7 \pm 10 \mathrm{mmHg})$, $\mathrm{p}<0.01)$ as compared to pre-RDN. Ambulatory BP decreased $-7 \pm 16 /-3 \pm 9 \mathrm{mmHg}(p>0.05)$ at 12 -month follow-up as compared to pre-RDN.

Conclusion This pilot study suggests that RDN might be able to decrease AF burden in min/day as measured using an ICM, with a positive effect on QOL. Large-scale randomized trials are needed to prove the definite value of RDN in hypertensive patients with atrial fibrillation.
\end{abstract}

Keywords Renal sympathetic denervation $\cdot \mathrm{RDN} \cdot$ Atrial fibrillation $\cdot \mathrm{AF} \cdot$ Implantable cardiac monitor $\cdot$ Quality of life

\section{Introduction}

$\mathrm{AF}$ is the most common arrhythmia worldwide, occurring in $2-3 \%$ of the adult population [1]. The incidence of AF, along with an inherent risk for thromboembolic events, increases with age and the presence of hypertension [2]. Vice versa, hypertension is the most common cardiovascular condition responsible for the development and recurrence of AF [3]. $\mathrm{AF}$ is associated with an impaired quality of life (QOL) and

Electronic supplementary material The online version of this article (https://doi.org/10.1007/s00392-018-1391-3) contains supplementary material, which is available to authorized users.

Joost Daemen

j.daemen@erasmusmc.nl

1 Department of Cardiology, Thoraxcenter, Erasmus University Medical Center, Room Rg6, P.O. Box 2040, 3000 CA Rotterdam, The Netherlands is known to increase the risk of hospitalization by two- to threefold resulting in increased health care costs [4]. In general, the current treatment options for AF can be divided into either pharmacological and/or ablation therapy (i.e. pulmonary vein isolation, PVI), performed either by percutaneous or surgical techniques. Despite improving tools and techniques, many patients remain symptomatic and side effects of pharmacological treatment are common with high recurrence rates following catheter ablation, especially in patients with hypertension [5-7]. Furthermore, major complications as tamponade and stroke have been reported in up to $4.5 \%$ of the patients treated with percutaneous techniques, while the impact on survival associated with any of the therapies mentioned above is still disputed [8]. Previous pathophysiological studies described a correlation of AF burden to hyperactivity of the sympathetic nervous system (SNS) and demonstrated that, by modulating the SNS directly, AF control might improve significantly [9-11]. While renal 
sympathetic denervation (RDN) has been studied to help control hypertension [12], its potential value in improving signs and symptoms of AF is currently unknown. The aim of the present pilot study was to assess if RDN decreases occurrence and symptoms of AF in patients with symptomatic paroxysmal or persistent AF at 6- and 12-month follow-up.

\section{Methods}

\section{Study design and patient population}

This study is a single-arm pilot study including 20 patients. Patients were eligible for enrolment if all of the following inclusion criteria were met: paroxysmal or persistent $\mathrm{AF}$, hypertension (mean office systolic $\mathrm{BP} \geq 140 \mathrm{mmHg}$ ), use of $\geq 2$ antihypertensive drugs, age $\geq 18$ years, estimated glomerular filtration rate (eGFR) $>45 \mathrm{ml} / \mathrm{min} / 1.73 \mathrm{~m}^{2}$. Paroxysmal AF was defined as an episode of AF that terminated spontaneously in less than 7 days. Persistent AF was defined as $\mathrm{AF}$ that fails to terminate in 7 days and an intervention was needed to restore sinus rhythm (pharmacologic or electrical cardioversion).

Patients with permanent AF, renal artery abnormalities, first episode of AF, comorbidities with a life expectancy of less than 1 year or unwillingness to undergo RDN or ICM implantation or follow-up visits were excluded. Secondary causes for hypertension were excluded prior to enrolment. The study was approved by our local ethics committee and all patients provided written informed consent (trialregister. nl, NTR number: NTR5329).

\section{Study measurements and endpoints}

Clinical and laboratory data were obtained at 1, 3, 6 and 12 months post-RDN; annual follow-up will be continued up to 3 years. The primary efficacy objective, AF burden, was measured with the SJM Confirm DM2102 ICM (St. Jude Medical, St Paul, MN, USA) featuring both an automatic and a manual activation trigger, AF triggers, heart rate histograms, mean heart rate and ventricular rate response (VRR) monitoring during AF. The primary safety objective was defined as a composite of death from cardiovascular causes, stroke, major access site bleeding, acute kidney injury or renal artery stenosis.

Serious adverse events (SAE's) and adverse events reported spontaneously by the subject or observed at each follow-up or any time in between, were recorded by the investigator. A SAE was defined as follows: any untoward medical occurrence, or effect, which in any dose results in events that were fatal or life-threatening, or that required a prolonged hospitalization; as well as any other important medical event that required intervention.
Secondary outcomes included change in office BP, ambulatory blood pressure measurements (ABPM), change in $24 \mathrm{~h}$-holter monitoring, change in echocardiographic parameters (change in left ventricular (LV) and left atrial (LA) volumes and dimensions and change in LV diastolic function) and QOL measurements (using the AFEQT questionnaire). The AFEQT questionnaire is an AF-specific health related QOL questionnaire designed to be used in different clinical settings and for research purposes to assess the impact of AF on patients QOL. Overall or subscale scores range from 0 (complete disability or limitations) to 100 (no disability or limitations) [13].

Office BP was measured at each follow-up visit with an automatic blood pressure monitor (Omron M10-IT). ABPM was performed using the Ultralite Ambulatory Blood Pressure monitor (Spacelabs Healthcare, model 90217A) and $24 \mathrm{~h}$-holter monitoring was performed with the evo digital recorder (Del Mar Reynolds, Spacelabs Healthcare) to assess changes in (supra) ventricular ectopic beats (S)VE beats.

We aimed to maintain the antihypertensive and antiarrhythmic drug regimen during the course of the study in all patients; however, changes were allowed in case of hypotension, hypertension or frequent $\mathrm{AF}$ episodes.

\section{ICM implantation and interrogation}

ICM [SJM Confirm DM2102 (St. Jude Medical, St Paul, MN, USA)] implantation was performed by an electrophysiologist under local anesthesia 3 months pre RDN. A small incision (about $2-3 \mathrm{~cm}$ ) was made lateral to the sternum at the level of the fourth and the fifth intercostal spaces. After the procedure, patients were instructed to use the activator in case of symptoms. To measure AF burden, the ICM was interrogated at each study visit per protocol by an expert (DT) to obtain the following parameters: functional status of the device, device battery level, analysis of any abnormal heart rhythms (AF, tachycardia, bradycardia and asystole) along with the highest VRR during AF episodes.

Final AF burden was assessed by confirming the AF episodes on the ECG readings to prevent false positive and false negative results. The minimum arrhythmia duration for an appropriate AF episode to be recorded was $30 \mathrm{~s}$ and a tachycardia cut-off rate of $120 \mathrm{bpm}$ was applied. Final outcomes were based on 3-month intervals; pre-RDN (0-3 months pre- procedure), 6 months (3-6 months post-RDN) and 12 months (9-12 months post-RDN). AF burden was defined as the average minutes/day spent in AF. Prior to procedure a total of $2 / 20$ patients with persistent AF progressed to permanent $\mathrm{AF}$ when using data derived from the long-term ECG recordings through ICM, both patients were excluded from the assessment of the primary outcome due to inequivalent burdens of $\mathrm{AF}$ as compared to patients with paroxysmal or persistent AF. 


\section{RDN procedure}

All patients were preloaded with $300 \mathrm{mg}$ aspirin, if naïve, and advised to continue with aspirin for at least 1 month. Pre-procedurally, $100 \mathrm{IU}$ heparin $/ \mathrm{kg}$ was administered to achieve an active clotting time $>250 \mathrm{~s}$. All procedures were performed under conscious sedation. After administration of local anesthesia, common femoral artery access was achieved by an ultrasound-guided puncture and a 6-Fr sheath was then introduced. Under fluoroscopic guidance, the short 6-Fr sheath was exchanged for an 8-Fr RDN or an IMA-tipped guiding sheath, to accommodate the St. Jude EnligHTN ${ }^{\mathrm{TM}}$ system. After smoothly engaging the renal arteries by using a no-touch technique with the help of a standard high-torque BHW coronary guidewire, selective renal artery angiograms were made and an appropriate basket size was chosen (small basket 4.0-5.5 mm diameter/ large basket 5.5-8.0 $\mathrm{mm}$ diameter). The BHW guidewire was exchanged for the EnligHTN ${ }^{\mathrm{TM}}$ ablation catheter with its tip proximal to the bifurcation of the main renal artery. The basket catheter, containing four bipolar Platinum-Iridium electrodes, was then opened with the impedance of each electrode on the basket monitored. After a total of four ablations were performed successfully the basket was collapsed and retracted proximally while another four ablations were performed in the same artery, with the intention to achieve at least eight successful ablations per artery.

\section{Statistical analysis}

Continuous variables were expressed as mean \pm standard deviation (SD) when normally distributed; non-normally distributed variables were presented as median [interquartile range, IQR]. Categorical variables were expressed as percentages. Continuous variables were using Student's $t$ test. Categorical variables were compared with the Chi square test or Fisher's Exact test when appropriate. The Wilcoxon signed-rank test or McNemar's test were performed to analyse the AF burden. Spearman correlation coefficient was used to evaluate the relationship between blood pressure drop and the change in AF burden. The Friedman test was performed to analyse EHRA class. All statistical tests are 2 -tailed. A $p$ value $<0.05$ was considered statistically significant. Statistical analysis was performed using SPSS statistical analysis (version 21.0).

\section{Results}

Between July 2014 and February 2016 a total of 136 patients were screened for eligibility. Twenty patients (14.7\%) met the inclusion criteria (Fig. 1). Baseline characteristics are presented in Table 1. In brief, nine patients were males and mean age was $64 \pm 7$ years. Mean office blood pressure was $153 / 88 \mathrm{mmHg}$. Most patients were on rhythm control $(19 / 20)$ and $20 \%$ of the patients had a history of pulmonary vein isolation. Timing between the RDN- and the previous PVI-procedure in 4/20 patients was $916 \pm 116$ days. Based on ambulatory BP measurements a total of 11 patients had essential hypertension according the definitions of the European Society of Hypertension [14] and nine patients had white coat uncontrolled hypertension. None of the patients had a history of obstructive sleep apnea syndrome.

AF burden decreased at 6 and 12 months. AF burden (min/day) was $1.39(0-10.9)$ pre-RDN vs. $0.67(0-31.6)$ at 6 months $(p=0.64)$ and $0.94(0-6.0)$ at 12 months $(p=0.03)$. Changes in AF episodes and change in the total minutes in AF are presented in Table 2.

Two patients progressed from persistent $\mathrm{AF}$ to permanent AF prior to RDN and were excluded from AF burden analysis. Both patients underwent failed attempts to restore sinus rhythm by ECV. Despite persistent EHRA class II on rate control both patients declined PVI during the course of the study.A sub analysis in patients with a history of PVI and an additional RDN showed a numerical decrease in AF burden $\mathrm{min} /$ day at 6 months and 1 year follow-up, from a median of $973 \mathrm{~min}(11.1-1440)$ to $12.9 \mathrm{~min}(3.7-22.8)$ at 6 months to $1.57(0.5-27.3)$ at 1 year ( $p>0.05$ for both).

Renal function remained unchanged at both 6- and 12-month follow-up, eGFR ( $\mathrm{ml} / \mathrm{min})$ pre-RDN was $83 \pm 20$ vs. $86 \pm 21$ at 6 months $(p=0.23)$ and $86 \pm 23$ at 12 months $(p=0.14)$. No cases of cardiovascular death, stroke, major access site bleeding, acute kidney injury or renal artery stenosis were reported. One peri-procedural complication was reported involving a renal artery dissection that resolved after balloon dilatation.

Office systolic BP decreased from $153 \pm 17 \mathrm{mmHg}$ preprocedure to $148 \pm 17 \mathrm{mmHg}$ at 6 months $(p=0.13)$ and to $133 \pm 16$ at 12 -month follow-up $(p<0.01)$ (Table 3$)$. No correlation was found between $\Delta \mathrm{BP}(\mathrm{ABPM})$ and $\Delta \mathrm{AF}$ burden (in terms of min/day or episodes); at 12 months ( $\Delta$ number of AF episodes and $\Delta$ mean 24 h systolic ABPM $r=-0.09$; $p=0.74$ and $\Delta \mathrm{AF}$ min/day and $\Delta$ mean $24 \mathrm{~h}$ systolic ABPM, $r=0.30 ; p=0.28$ ).

Mean heart rate on $24 \mathrm{~h}$-holter monitoring remained unchanged at 6 - months $(-5 \pm 14 \mathrm{bpm} ; p=0.15)$ and 12-month follow-up ( $-1 \pm 14 \mathrm{bpm} ; p=0.63)$ as compared to baseline. A numerical decrease was seen in SVE beats at 6- and 12-month follow-up as compared to pre-procedure. VE beats remained unchanged during follow-up (Table 4). EHRA class improved significantly at both 6 and 12 months as compared to pre-RDN $(p<0.01)$ (Fig. 2).

None of the patients underwent PVI within 1 year followup post-RDN.

No change was found in LV and LA volumes and dimensions at 6- and 12 months post RDN (Supplement, Table S1). 
Fig. 1 Screening process based on inclusion- and exclusion criteria. $A F$ atrial fibrillation, antiHT antihypertensive medication, $B M I$ body mass index, EHRA European Heart Rhythm Association, $H T$ hypertension, $P V I$ pulmonary vein isolation

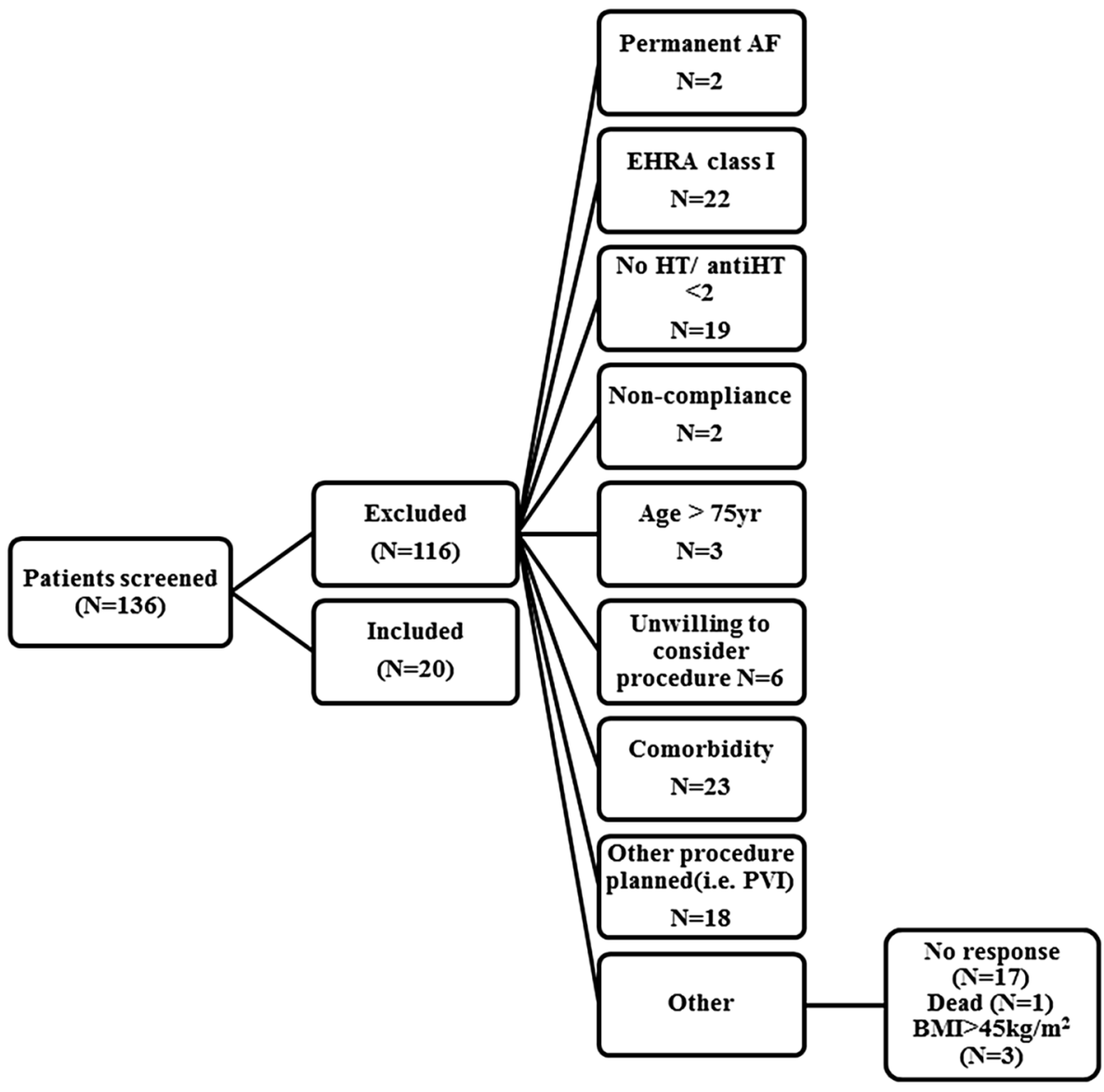

QOL improved significantly at both follow-up visits (as compared to pre-procedure; $+11 \pm 15$ points at 6 months, $p<0.01$ and $+10 \pm 19$ at 12 months, $p=0.04$ ) (Fig. 3).

A total of 3/20 (15\%) patients underwent an ECV post $\mathrm{RDN}$ due to recurrence of $\mathrm{AF}$ at 6 months; the average period to perform the first ECV post-RDN in these patients was $134 \pm 83$ days. In two out of these three patients a second ECV was done and one patient received a total of three ECV's during follow-up.

Despite efforts in maintaining initial drug regimens during the course of the study, antiarrhythmic drugs or drug dosages were increased in $3 / 20$ patients (these were different patients from who underwent an ECV) and decreased in 6/20 patients. Antihypertensive medication was increased in $2 / 20$ patients and decreased or stopped in 4/20 patients.

\section{Discussion}

This single-center pilot study suggests that RDN was able to significantly decrease AF burden in min/day as measured using an ICM, together with an improvement in QOL. Finally, RDN appeared safe with a positive effect on blood pressure.
Sympathetic hyperactivity has been considered an important source for the induction and maintenance of arrhythmias [15]. Previous studies provided evidence for the presence of increased atrial sympathetic activity in both persistent and paroxysmal AF, suggesting autonomic remodeling may be part of the atrial substrate for $\mathrm{AF}[16,17]$.

Pathophysiological studies demonstrated that by modulating the SNS through RDN, AF control might improve [18]. Linz and colleagues demonstrated the effect of RDN on heart rate and VRR in pigs with permanent AF; the authors described a reduction of $24 \%$ in VRR in the treated pigs vs. sham [19]. Furthermore, the potential effects of RDN on ventricular electrophysiological properties should be mentioned. Huang and colleagues demonstrated that RDN could alter the ventricular effective refractory period (ERP) and action potential duration (APD) in eight dogs as compared to a sham operation group $(N=8)$ [20]. The authors described a prolongation of ventricular APD after RDN, which hypothetically could prevent the occurrence of fatal ventricular arrhythmias (VA). A multicenter registry reported that RDN appeared to be safe and efficacious in reducing VA burden in patients with chronic heart failure; the procedure was performed in patients with a few or no further therapeutic options [21]. Finally, successful anecdotal experience was 
Table 1 Baseline characteristics of the study population

\begin{tabular}{|c|c|}
\hline \multicolumn{2}{|c|}{ Total study population $(N=20)$} \\
\hline Age, years & $64 \pm 7$ \\
\hline Male $n,(\%)$ & $9(45)$ \\
\hline BMI $\left(\mathrm{kg} / \mathrm{m}^{2}\right)$ & $30.7 \pm 5.6$ \\
\hline Paroxysmal AF $n,(\%)$ & $18(90)$ \\
\hline EHRA class II & $15(75)$ \\
\hline EHRA class III & $5(25)$ \\
\hline Mean heart rate (bpm) & $71 \pm 15$ \\
\hline Office BP (mmHg) & $153 \pm 17 / 88 \pm 11$ \\
\hline Ambulatory BP (mmHg) & $130 \pm 15 / 77 \pm 9$ \\
\hline \multicolumn{2}{|c|}{ Cardiovascular risk factors $n,(\%)$} \\
\hline Diabetes & $2(10)$ \\
\hline Hypertension & $20(100)$ \\
\hline Dyslipidemia & $8(40)$ \\
\hline Smoking & $1(5)$ \\
\hline Family history of IHD & $4(20)$ \\
\hline \multicolumn{2}{|c|}{ Cardiovascular history $n,(\%)$} \\
\hline Prior PVI & $4(20)$ \\
\hline Prior CVA & $2(10)$ \\
\hline \multicolumn{2}{|l|}{ Antiarrhythmic drugs $n,(\%)$} \\
\hline Class I & $4(20)$ \\
\hline Class II & $1(5)$ \\
\hline Class III & $12(60)$ \\
\hline Class V & $2(10)$ \\
\hline \multicolumn{2}{|c|}{ Antihypertensive drugs $n,(\%)$} \\
\hline ACE-i & $7(35)$ \\
\hline $\mathrm{ARB}$ & $8(40)$ \\
\hline Beta-blockers $^{\mathrm{a}}$ & $18(90)$ \\
\hline $\mathrm{CCB}$ & $10(50)$ \\
\hline Alfa-blocker & $3(15)$ \\
\hline Diuretics & $13(65)$ \\
\hline
\end{tabular}

Values are mean $\pm \mathrm{SD}$ or $n(\%)$

$A F$ atrial fibrillation, $B M I$ body mass index, $B P$ blood pressure, $C V A$ cerebrovascular accident, EHRA European Heart Rhythm Association, $I H D$ ischemic heart disease, $P V I$ pulmonary vein isolation

a $2 / 20$ patients were intolerant for beta-blockers achieved with RDN in patients with refractory vasospasticinduced ventricular tachycardia [22]. The findings, however, do suggest that RDN might be a potentially more appealing option to modify cardiac electrophysiological properties as compared to pivotal work on cardiac catheter ablation which proved to shorten the ERP and increase the incidence of premature ventricular complexes [23]. Of note, in the present study, no changes were observed over time in the incidence of ventricular ectopic beats.

Several recent randomized sham controlled trials proved the blood pressure lowering effect of RDN in both hypertensive patients taken off medication as well as in patients with uncontrolled hypertension, respectively [12, 24-26]. The multi-electrode EnligHTNTM catheter showed to decrease BP based on ABPM and to reduce renal norepinephrine in previous animal studies [27, 28]. Specifically related to the present human study, similar BP lowering effect was observed with the same catheter in patients with treatmentresistant hypertension [29].

Besides the antihypertensive effects of RDN, an experimental study by Tsai and colleagues showed the antiarrhythmic effects of RDN in six ambulatory dogs by measuring lower nerve activity at the level of the stellate ganglion with also a decrease in paroxysmal atrial tachycardia episodes and duration after RDN as compared to controls [10]. Moreover, two clinical studies assessed the antiarrhythmic effect of RDN in addition to PVI in hypertensive patients with symptomatic AF. One of these studies demonstrated a positive correlation between the decrease in mean BP and the decline in AF burden. A reduction of $5-10 \mathrm{mmHg}$ in mean $\mathrm{BP}$ led to a $7 \%$ decrease in mean AF burden as measured with an ICM [30]. Unfortunately, in the present study, we were not able to show a clear correlation between the change in blood pressure and change in AF burden following RDN. Pokushalov and colleagues showed that RDN on top of PVI in patients with symptomatic $\mathrm{AF}$ and resistant hypertension reduced the incidence of AF recurrence rates significantly. At 1 year, based on 24 h-holter monitoring, $69 \%$ of the patients in the PVI + RDN were free of AF episodes, while in the PVI only group, only $29 \%$ of the patients remained free of AF
Table 2 AF burden on ICM monitors pre-RDN vs. 6- and 12-month follow-up

\begin{tabular}{llllll}
\hline & Pre-RDN & 6 months & 12 months & $p^{*}$ & $p^{* *}$ \\
\hline AF episodes $(n)$ & $1(0-11)$ & $1(0-11)$ & $3(0-16)$ & 0.84 & 0.31 \\
Total episodes AF (min) & $125(2-978)$ & $44(0-2833)$ & $84(0-544)$ & 0.64 & 0.03 \\
AF min/day & $1.39(0-10.9)$ & $0.67(0-31.6)$ & $0.94(0-6.0)$ & 0.64 & 0.03 \\
Highest VRR (bpm) & $127(105-145)$ & $117(104-141)$ & $106(75-126)$ & 0.09 & 0.01
\end{tabular}

Values are in median [IQR]

$A F$ atrial fibrillation, ICM implantable cardiac monitor, $V R R$ ventricular rate response during $\mathrm{AF}$

*Between pre-RDN vs. 6 months, **pre-RDN vs. 12 months. Results are based on 18/20 patients, and patients with permanent $\mathrm{AF}$ were excluded 
Table 3 Office and ambulatory blood pressure change pre-RDN vs. 6- and 12-month follow-up

\begin{tabular}{lccccc}
\hline & Pre-RDN & 6 months & 12 months & $p^{*}$ & $p^{* *}$ \\
\hline Office systolic BP (mmHg) & $153 \pm 17$ & $148 \pm 17$ & $133 \pm 16$ & 0.13 & $<0.01$ \\
Office diastolic BP (mmHg) & $89 \pm 10$ & $81 \pm 11$ & $81 \pm 10$ & 0.006 & 0.007 \\
24 h ABPM systolic (mmHg) & $131 \pm 16$ & $121 \pm 9$ & $124 \pm 11$ & 0.007 & 0.07 \\
24 h ABPM diastolic (mmHg) & $78 \pm 9$ & $72 \pm 6$ & $74 \pm 9$ & 0.006 & 0.16 \\
\hline
\end{tabular}

Values are mean $\pm \mathrm{SD}$

$A B P M$ ambulatory blood pressure measurement, $B P$ blood pressure

*Pre-RDN vs. 6 months

**Pre-RDN vs. 12 months
Table 424 h-holter monitoring for (S)VE beats

\begin{tabular}{llllll}
\hline & Pre-RDN & 6 months & 12 months & $p^{*}$ & $p^{* *}$ \\
\hline $\begin{array}{c}\text { Heart rate } \\
\text { (bpm) }\end{array}$ & $71 \pm 15$ & $66 \pm 8$ & $70 \pm 12$ & 0.15 & 0.63 \\
SVE (beats) & 187 & 137 & $79(13-763)$ & 0.36 & 0.05 \\
VE (beats) & $35(3-153)$ & $22(3-86)$ & $42(5-134)$ & 0.57 & 0.73 \\
\hline
\end{tabular}

Values are mean \pm SD or are median [IQR]

(S)VE (supraventricular)ectopic beats

*Pre-RDN vs. 6 months

**Pre-RDN vs. 12 months

episodes [6]. A dedicated prospective randomized controlled trial is currently ongoing to determine the efficacy of RDN on top of PVI in patients with hypertension [31] (Clinicaltrials.gov, NCT02115100).
It can be hypothesized that the antiarrhythmic effects of RDN could be due to a synergistic effect of (a) better BP control (partly) withdrawing an important risk factor for $\mathrm{AF}$ recurrence and (b) improving AF control by modifying electrophysiological settings like prolongation of the atrial effective refractory period [3, 32]. AF burden (in min/day and episodes) decreased significantly at 1 year follow-up; however, it did not reach statistical significance at 6 months' follow-up. Although the latter could be due to the fact that the variability in AF burden at 6 months was high, an increasing effect of RDN over time could not be excluded. In the recently published SPYRAL-ON MED trial, BP reduction was greater at 6 months as compared with 3 months [33].

To the best of our knowledge, the present work is the first clinical study to demonstrate that RDN, without concomitant PVI, may reduce AF burden as measured using an ICM. Measuring AF burden with an ICM is superior to intermittent $\mathrm{AF}$ event monitoring using $24 \mathrm{~h}$-holters or event
Fig. 2 Change in EHRA class at follow-up visits (6- and 12 months results). EHRA European Heart Rhythm Association, pre-RDN prior to renal sympathetic denervation, $6 M 6$ months, $12 M 12$ months

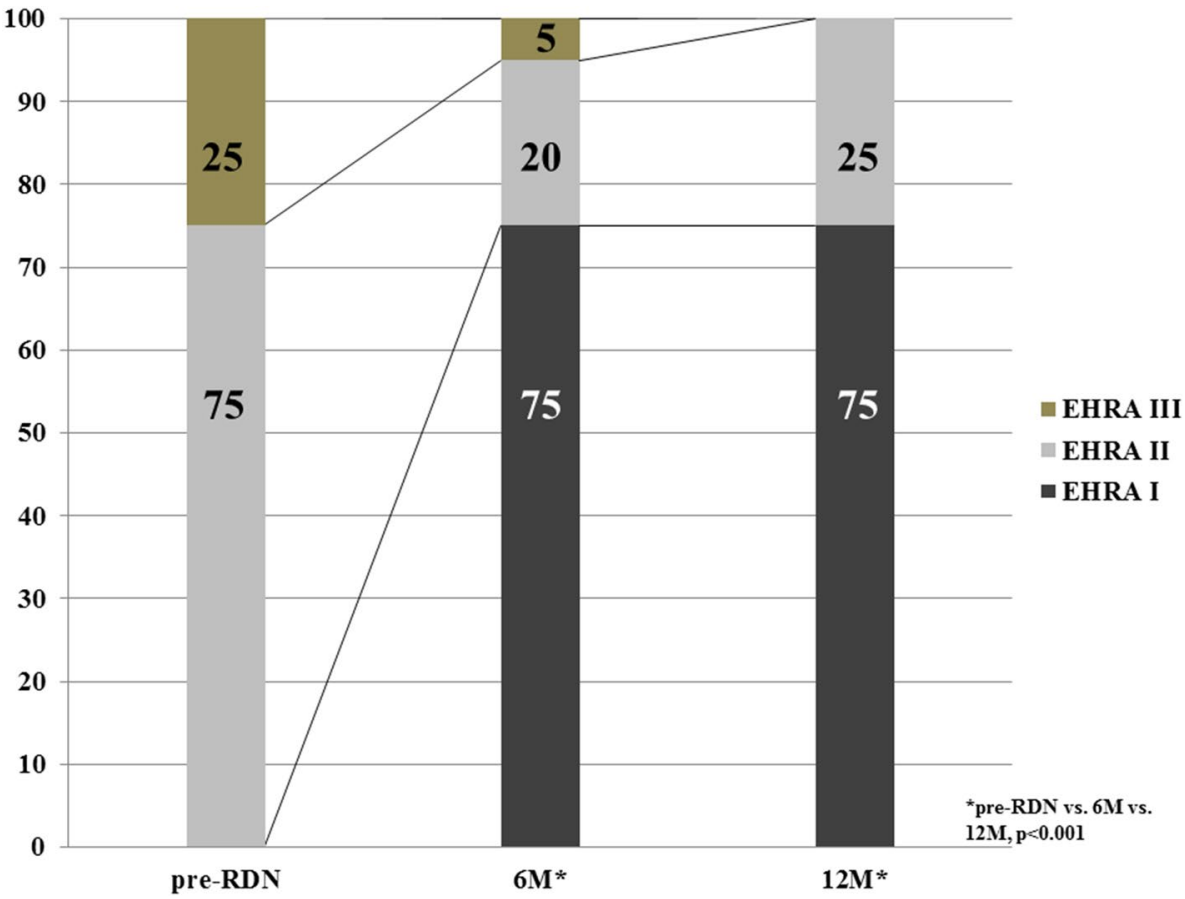




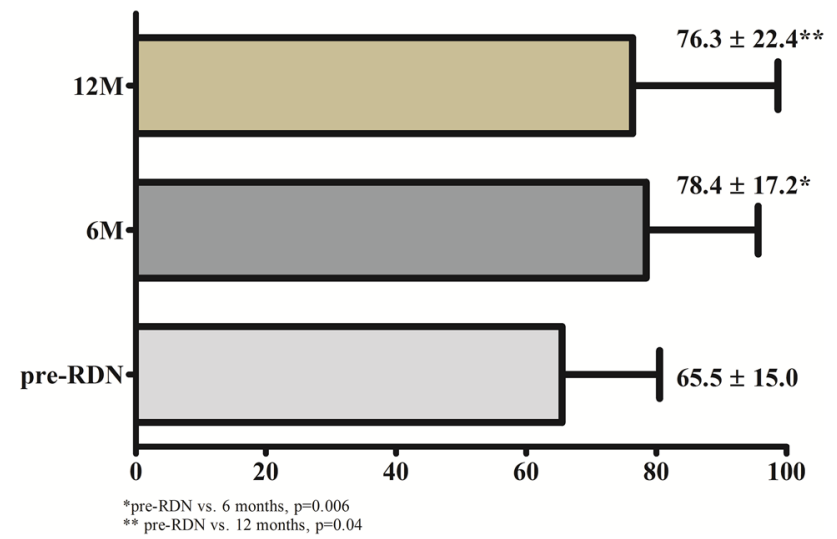

Fig. 3 AFEQT questionnaire. pre-RDN prior to renal sympathetic denervation, $6 M 6$ months, $12 M 12$ months

recorders [34]. Monitoring treatment effect based on symptoms alone is unreliable since approximately $50 \%$ of $\mathrm{AF}$ recurrences proved to occur in asymptomatic patients [35]. Vice versa, Padeletti and colleagues showed a high intrapatient burden variability and demonstrated that only $52 \%$ of patient symptoms appear to be correlated to documented AF [36]. The latter was confirmed in our study in which we found a clear discrepancy between pre-procedural EHRA class and the actual AF episodes as measured using either 24 h-holter or ICM. Nevertheless, despite a large variability in AF burden between patients we were able to demonstrate a significant reduction in AF burden post RDN.

Of note, despite their known limitations, the vast majority of previous studies assessing the efficacy of either PVI or surgical ablation used intermittent and symptom-based monitoring (i.e. $24 \mathrm{~h}$ holter monitoring or event monitors) to demonstrate their effect [37].

Finally, we were not able to demonstrate any changes in echocardiographic parameters and diastolic function in our study population, which could be due to either the small sample size or advanced stages of LA dilatation prior to study participation.

\section{Limitations}

Despite the positive results in this present study, there are several limitations that should be taken into account. First, it concerns a small study cohort $(N=20)$ in whom two patients progressed to permanent $\mathrm{AF}$ and were excluded from the analysis of AF burden. Second, in approximately $50 \%$ of the treated patients, we stopped or decreased drug dosages of antihypertensive and/or anti-arrhythmic drugs. Third, adherence to antihypertensive drugs was not measured and only confirmed by the physician at the outpatient clinic visit. Fourth, the ICM used in this study was not able to transmit wirelessly the ECG to the office, which could have led to an underestimation of the AF events in case of data overload and a lack of memory (which occurred in 1/20 patient). Fifth, RDN was performed with the EnligHTNTM ablation catheter which enabled the operator to ablate only in the main renal arteries and is currently no longer available for clinical use. Whether the use of current generation devices using different technologies as ultrasound, ethanol or RF sidebranch ablation would have resulted in more potent results remains to be determined. Finally, since no sham control group was included in the present pilot study, the potential of a placebo effect cannot be ruled out. Nevertheless, we showed the potential value of RDN in patients with paroxysmal $\mathrm{AF}$ and warrants the conduction of larger and sham controlled studies assessing the anti-arrhythmic effect of RDN.

\section{Conclusion}

This pilot study suggests that RDN was safe and able to decrease AF burden in min/day as measured using an ICM at 12-month follow-up, together with an improvement in QOL in patients with symptomatic paroxysmal or persistent AF. Large-scale randomized trials are needed to demonstrate the value of RDN in hypertensive patients with $\mathrm{AF}$.

Funding This work was supported by St. Jude Medical, St Paul, MN, USA/Abbott Vascular, Santa Clara, California, USA.

\section{Compliance with ethical standards}

Ethical statement This study has been approved by our ethics committee and was therefore performed in accordance with the ethical standards laid down in the 1964 Declaration of Helsinki and its later amendments.

Conflict of interest Joost Daemen received institutional research support from Abbott Vascular, Medtronic, Boston Scientific, Acist and Pie Medical as well as speaker and consultancy fees from Medtronic, Acist, Pythagoras. The other authors have no conflicts of interest to declare.

Open Access This article is distributed under the terms of the Creative Commons Attribution 4.0 International License (http://creativeco mmons.org/licenses/by/4.0/), which permits unrestricted use, distribution, and reproduction in any medium, provided you give appropriate credit to the original author(s) and the source, provide a link to the Creative Commons license, and indicate if changes were made.

\section{References}

1. Haim M, Hoshen M, Reges O, Rabi Y, Balicer R, Leibowitz M (2015) Prospective national study of the prevalence, incidence, management and outcome of a large contemporary cohort of 
patients with incident non-valvular atrial fibrillation. J Am Heart Assoc 4(1):e001486. https://doi.org/10.1161/JAHA.114.001486

2. Jahangir A, Lee V, Friedman PA, Trusty JM, Hodge DO, Kopecky SL, Packer DL, Hammill SC, Shen WK, Gersh BJ (2007) Long-term progression and outcomes with aging in patients with lone atrial fibrillation: a 30-year follow-up study. Circulation 115(24):3050-3056. https://doi.org/10.1161/CIRCULATIO NAHA.106.644484

3. Manolis AJ, Rosei EA, Coca A, Cifkova R, Erdine SE, Kjeldsen S, Lip GY, Narkiewicz K, Parati G, Redon J, Schmieder R, Tsioufis C, Mancia G (2012) Hypertension and atrial fibrillation: diagnostic approach, prevention and treatment. Position paper of the Working Group 'Hypertension Arrhythmias and Thrombosis' of the European Society of Hypertension. J Hypertens 30(2):239252. https://doi.org/10.1097/HJH.0b013e32834f03bf

4. Chugh SS, Havmoeller R, Narayanan K, Singh D, Rienstra M, Benjamin EJ, Gillum RF, Kim YH, McAnulty JH Jr, Zheng ZJ, Forouzanfar MH, Naghavi M, Mensah GA, Ezzati M, Murray CJ (2014) Worldwide epidemiology of atrial fibrillation: a Global Burden of Disease 2010 Study. Circulation 129(8):837-847. https ://doi.org/10.1161/CIRCULATIONAHA.113.005119

5. Corley SD, Epstein AE, DiMarco JP, Domanski MJ, Geller N, Greene HL, Josephson RA, Kellen JC, Klein RC, Krahn AD, Mickel M, Mitchell LB, Nelson JD, Rosenberg Y, Schron E, Shemanski L, Waldo AL, Wyse DG, Investigators A (2004) Relationships between sinus rhythm, treatment, and survival in the Atrial Fibrillation Follow-Up Investigation of Rhythm Management (AFFIRM) Study. Circulation 109(12):1509-1513. https://doi. org/10.1161/01.CIR.0000121736.16643.11

6. Pokushalov E, Romanov A, Corbucci G, Artyomenko S, Baranova V, Turov A, Shirokova N, Karaskov A, Mittal S, Steinberg JS (2012) A randomized comparison of pulmonary vein isolation with versus without concomitant renal artery denervation in patients with refractory symptomatic atrial fibrillation and resistant hypertension. J Am Coll Cardiol 60(13):1163-1170. https:// doi.org/10.1016/j.jacc.2012.05.036

7. Mahfoud F, Schmieder RE, Azizi M, Pathak A, Sievert H, Tsioufis C, Zeller T, Bertog S, Blankestijn PJ, Bohm M, Burnier M, Chatellier G, Durand Zaleski I, Ewen S, Grassi G, Joner M, Kjeldsen SE, Lobo MD, Lotan C, Luscher TF, Parati G, Rossignol P, Ruilope L, Sharif F, van Leeuwen E, Volpe M, Windecker S, Witkowski A, Wijns W (2017) Proceedings from the 2nd European Clinical Consensus Conference for device-based therapies for hypertension: state of the art and considerations for the future. Eur Heart J 38(44):3272-3281. https://doi.org/10.1093/eurheartj/ ehx 215

8. Ouyang F, Tilz R, Chun J, Schmidt B, Wissner E, Zerm T, Neven K, Kokturk B, Konstantinidou M, Metzner A, Fuernkranz A, Kuck KH (2010) Long-term results of catheter ablation in paroxysmal atrial fibrillation: lessons from a 5-year follow-up. Circulation 122(23):2368-2377. https://doi.org/10.1161/CIRCULATIO NAHA. 110.946806

9. Chen PS, Tan AY (2007) Autonomic nerve activity and atrial fibrillation. Heart Rhythm 4(3 Suppl):S61-S64. https://doi. org/10.1016/j.hrthm.2006.12.006

10. Tsai WC, Chan YH, Chinda K, Chen Z, Patel J, Shen C, Zhao Y, Jiang Z, Yuan Y, Ye M, Chen LS, Riley AA, Persohn SA, Territo PR, Everett TH, Lin SF, Vinters HV, Fishbein MC, Chen PS (2017) Effects of renal sympathetic denervation on the stellate ganglion and brain stem in dogs. Heart Rhythm 14(2):255-262. https://doi.org/10.1016/j.hrthm.2016.10.003

11. Chen PS, Chen LS, Fishbein MC, Lin SF, Nattel S (2014) Role of the autonomic nervous system in atrial fibrillation: pathophysiology and therapy. Circ Res 114(9):1500-1515. https://doi. org/10.1161/CIRCRESAHA.114.303772
12. Azizi M, Sapoval M, Gosse P, Monge M, Bobrie G, Delsart P, Midulla M, Mounier-Vehier C, Courand PY, Lantelme P, Denolle T, Dourmap-Collas C, Trillaud H, Pereira H, Plouin PF, Chatellier G, Renal Denervation for Hypertension i (2015) Optimum and stepped care standardised antihypertensive treatment with or without renal denervation for resistant hypertension (DENERHTN): a multicentre, open-label, randomised controlled trial. Lancet 385(9981):1957-1965. https://doi.org/10.1016/S0140 -6736(14)61942-5

13. Spertus J, Dorian P, Bubien R, Lewis S, Godejohn D, Reynolds MR, Lakkireddy DR, Wimmer AP, Bhandari A, Burk C (2011) Development and validation of the atrial fibrillation effect on quality-of-life (AFEQT) questionnaire in patients with atrial fibrillation. Circ Arrhythm Electrophysiol 4(1):15-15+. https:// doi.org/10.1161/Circep.110.958033

14. Parati G, Stergiou G, O’Brien E, Asmar R, Beilin L, Bilo G, Clement D, de la Sierra A, de Leeuw P, Dolan E, Fagard R, Graves J, Head GA, Imai Y, Kario K, Lurbe E, Mallion JM, Mancia G, Mengden T, Myers M, Ogedegbe G, Ohkubo T, Omboni S, Palatini P, Redon J, Ruilope LM, Shennan A, Staessen JA, vanMontfrans $G$, Verdecchia $P$, Waeber B, Wang J, Zanchetti A, Zhang Y, European Society of Hypertension Working Group on Blood Pressure M, Cardiovascular V (2014) European Society of Hypertension practice guidelines for ambulatory blood pressure monitoring. J Hypertens 32(7):1359-1366. https://doi. org/10.1097/HJH.0000000000000221

15. Yu L, Huang B, Wang Z, Wang S, Wang M, Li X, Zhou L, Meng G, Yuan S, Zhou X, Jiang H (2017) Impacts of renal sympathetic activation on atrial fibrillation: the potential role of the autonomic cross talk between kidney and heart. J Am Heart Assoc. https:// doi.org/10.1161/JAHA.116.004716

16. Gould PA, Yii M, McLean C, Finch S, Marshall T, Lambert GW, Kaye DM (2006) Evidence for increased atrial sympathetic innervation in persistent human atrial fibrillation. Pacing Clin Electrophysiol 29(8):821-829. https://doi.org/10.111 1/j.1540-8159.2006.00447.x

17. Choi EK, Shen MJ, Han S, Kim D, Hwang S, Sayfo S, Piccirillo G, Frick K, Fishbein MC, Hwang C, Lin SF, Chen PS (2010) Intrinsic cardiac nerve activity and paroxysmal atrial tachyarrhythmia in ambulatory dogs. Circulation 121(24):2615-2623. https://doi.org/10.1161/CIRCULATIONAHA.109.919829

18. Hou Y, Hu J, Po SS, Wang H, Zhang L, Zhang F, Wang K, Zhou Q (2013) Catheter-based renal sympathetic denervation significantly inhibits atrial fibrillation induced by electrical stimulation of the left stellate ganglion and rapid atrial pacing. PLoS One 8(11):e78218. https://doi.org/10.1371/journal.pone.0078218

19. Linz D, Mahfoud F, Schotten U, Ukena C, Hohl M, Neuberger HR, Wirth K, Bohm M (2013) Renal sympathetic denervation provides ventricular rate control but does not prevent atrial electrical remodeling during atrial fibrillation. Hypertension 61(1):225-231. https://doi.org/10.1161/HYPERTENSIONAHA.111.00182

20. Huang B, Yu L, He B, Wang S, Lu Z, Liao K, Wang Z, Zhou $X$, He W, Jiang H (2015) Sympathetic denervation of heart and kidney induces similar effects on ventricular electrophysiological properties. EuroIntervention 11(5):598-604. https://doi. org/10.4244/EIJV11I5A119

21. Ukena C, Mahfoud F, Ewen S, Bollmann A, Hindricks G, Hoffmann BA, Linz D, Musat D, Pavlicek V, Scholz E, Thomas D, Willems S, Bohm M, Steinberg JS (2016) Renal denervation for treatment of ventricular arrhythmias: data from an International Multicenter Registry. Clin Res Cardiol 105(10):873-879. https:// doi.org/10.1007/s00392-016-1012-y

22. Feyz L, Wijchers S, Daemen J (2017) Renal denervation as a treatment strategy for vasospastic angina induced ventricular tachycardia. Neth Heart J 25(10):596-597. https://doi.org/10.1007/s1247 1-017-1012-1 
23. Jungen C, Scherschel K, Eickholt C, Kuklik P, Klatt N, Bork N, Salzbrunn T, Alken F, Angendohr S, Klene C, Mester J, Klocker N, Veldkamp MW, Schumacher U, Willems S, Nikolaev VO, Meyer C (2017) Disruption of cardiac cholinergic neurons enhances susceptibility to ventricular arrhythmias. Nat Commun 8:14155. https://doi.org/10.1038/ncomms14155

24. Townsend RR, Mahfoud F, Kandzari DE, Kario K, Pocock S, Weber MA, Ewen S, Tsioufis K, Tousoulis D, Sharp ASP, Watkinson AF, Schmieder RE, Schmid A, Choi JW, East C, Walton A, Hopper I, Cohen DL, Wilensky R, Lee DP, Ma A, Devireddy CM, Lea JP, Lurz PC, Fengler K, Davies J, Chapman N, Cohen SA, DeBruin V, Fahy M, Jones DE, Rothman M, Bohm M, investigators* SH-OMt (2017) Catheter-based renal denervation in patients with uncontrolled hypertension in the absence of antihypertensive medications (SPYRAL HTN-OFF MED): a randomised, shamcontrolled, proof-of-concept trial. Lancet. https://doi.org/10.1016/ S0140-6736(17)32281-X

25. Kandzari DE, Bohm M, Mahfoud F, Townsend RR, Weber MA, Pocock S, Tsioufis K, Tousoulis D, Choi JW, East C, Brar S, Cohen SA, Fahy M, Pilcher G, Kario K, Investigators SH-OMT (2018) Effect of renal denervation on blood pressure in the presence of antihypertensive drugs: 6-month efficacy and safety results from the SPYRAL HTN-ON MED proof-of-concept randomised trial. Lancet 391(10137):2346-2355. https://doi.org/10.1016/ S0140-6736(18)30951-6

26. Azizi M, Schmieder RE, Mahfoud F, Weber MA, Daemen J, Davies J, Basile J, Kirtane AJ, Wang Y, Lobo MD, Saxena M, Feyz L, Rader F, Lurz P, Sayer J, Sapoval M, Levy T, Sanghvi K, Abraham J, Sharp ASP, Fisher NDL, Bloch MJ, Reeve-Stoffer H, Coleman L, Mullin C, Mauri L, Investigators R-H (2018) Endovascular ultrasound renal denervation to treat hypertension (RADIANCE-HTN SOLO): a multicentre, international, single-blind, randomised, sham-controlled trial. Lancet 391(10137):2335-2345. https://doi.org/10.1016/S0140 $-6736(18) 31082-1$

27. Mahfoud F, Moon LB, Pipenhagen CA, Jensen JA, Pathak A, Papademetriou V, Ewen S, Linz D, Bohm M (2016) Catheter-based radio-frequency renal nerve denervation lowers blood pressure in obese hypertensive swine model. J Hypertens 34(9):1854-1862. https://doi.org/10.1097/HJH.0000000000001021

28. Henegar JR, Zhang Y, Hata C, Narciso I, Hall ME, Hall JE (2015) Catheter-based radiofrequency renal denervation: location effects on renal norepinephrine. Am J Hypertens 28(7):909-914. https:// doi.org/10.1093/ajh/hpu258

29. Worthley SG, Tsioufis CP, Worthley MI, Sinhal A, Chew DP, Meredith IT, Malaiapan Y, Papademetriou V (2013) Safety and efficacy of a multi-electrode renal sympathetic denervation system in resistant hypertension: the EnligHTN I trial. Eur Heart J 34(28):2132-2140. https://doi.org/10.1093/eurheartj/eht197
30. Romanov A, Pokushalov E, Ponomarev D, Strelnikov A, Shabanov V, Losik D, Karaskov A, Steinberg JS (2017) Pulmonary vein isolation with concomitant renal artery denervation is associated with reduction in both arterial blood pressure and atrial fibrillation burden: data from implantable cardiac monitor. Cardiovasc Ther. https://doi.org/10.1111/1755-5922.12264

31. de Jong MR, Hoogerwaard AF, Adiyaman A, Smit JJJ, Ramdat Misier AR, Heeg JE, van Hasselt B, Van Gelder IC, Crijns H, Lozano IF, Toquero Ramos JE, Javier Alzueta F, Ibanez B, Rubio JM, Arribas F, Porres Aracama JM, Brugada J, Mont L, Elvan A (2018) Treatment of atrial fibrillation in patients with enhanced sympathetic tone by pulmonary vein isolation or pulmonary vein isolation and renal artery denervation: clinical background and study design: the ASAF trial: ablation of sympathetic atrial fibrillation. Clin Res Cardiol. https://doi.org/10.1007/s0039 2-018-1214-6

32. Wang X, Huang C, Zhao Q, Huang H, Tang Y, Dai Z, Wang X, Guo Z, Xiao J (2015) Effect of renal sympathetic denervation on the progression of paroxysmal atrial fibrillation in canines with long-term intermittent atrial pacing. Europace 17(4):647-654. https://doi.org/10.1093/europace/euu212

33. Kandzari DE, Bohm M, Mahfoud F, Townsend RR, Weber MA, Pocock S, Tsioufis K, Tousoulis D, Choi JW, East C, Brar S, Cohen SA, Fahy M, Pilcher G, Kario K, Investigators SH-OMT (2018) Effect of renal denervation on blood pressure in the presence of antihypertensive drugs: 6-month efficacy and safety results from the SPYRAL HTN-ON MED proof-of-concept randomised trial. Lancet. https://doi.org/10.1016/S0140-6736(18)30951-6

34. Ziegler PD, Koehler JL, Mehra R (2006) Comparison of continuous versus intermittent monitoring of atrial arrhythmias. Heart Rhythm 3(12):1445-1452. https://doi.org/10.1016/j.hrthm .2006.07.030

35. Cheung JW, Keating RJ, Stein KM, Markowitz SM, Iwai S, Shah BK, Lerman BB, Mittal S (2006) Newly detected atrial fibrillation following dual chamber pacemaker implantation. J Cardiovasc Electrophysiol 17(12):1323-1328. https://doi.org/10.11 11/j.1540-8167.2006.00648.x

36. Padeletti L, Santini M, Boriani G, Botto G, Capucci A, Gulizia M, Ricci R, Spampinato A, Pieragnoli P, Warman E, Vimercati M, Grammatico A (2005) Temporal variability of atrial tachyarrhythmia burden in bradycardia-tachycardia syndrome patients. Eur Heart J 26(2):165-172. https://doi.org/10.1093/eurheartj/ehi059

37. Wazni OM, Marrouche NF, Martin DO, Verma A, Bhargava M, Saliba W, Bash D, Schweikert R, Brachmann J, Gunther J, Gutleben K, Pisano E, Potenza D, Fanelli R, Raviele A, Themistoclakis S, Rossillo A, Bonso A, Natale A (2005) Radiofrequency ablation vs antiarrhythmic drugs as first-line treatment of symptomatic atrial fibrillation: a randomized trial. JAMA 293(21):2634-2640. https://doi.org/10.1001/jama.293.21.2634 